\title{
A Review on Soya Bean Oil Biodiesel - An Alternative Source of Fuel
}

\author{
Dr. Rita Bajpai \\ Department of Chemistry, Dr. J.P.M. Govt. Sc. College, Mungli (C.G.) India
}

\begin{abstract}
As the world energy demand is continuously increasing, the most sufficient way to meet the growing demand is by finding alternative fuels. From the point of environment protection, finding alternative fuels that are sustainable and environment friendly is essential. The study of biodiesel because the continuous exploration and consumption of fossil fuels have led to a decline in worldwide oil reserves. Biodiesel is monoalkyl esters of long chain fatty acid derived from the renewable sources like soyabean vegetable oil, which is produced by transesterification of vegetable (soyabean) oil. This paper includes isolation and analysis of alternative source of fuel and the reported yield is $85 \%$.
\end{abstract}

Keywords: biodiesel, alternative source, fossil fuels, soyabean vegetable oil, transesterification \& environment friendly

\section{Introduction}

Biodiesel is the name for a variety of ester-based fuels (fatty esters) generally defined as the monoalkyl esters made from vegetable oils, such as soybean oil, canola or hemp oil, or sometimes from animal fats through a simple transesterification process. Biodiesel is a biodegradable and non-toxic alternative fuel produced from new or used vegetable oil that is produced from renewable resources.

It can be used in any Diesel engine without modification. Rudolf Diesel (1858-1913) developed the first engine to run on peanut oil, as he demonstrated at the World Exhibition in Paris in 1900. Unfortunately, R. Diesel died 1913 before his vision of a vegetable oil powered engine was fully realized. According to the environmental worries and the consumption of non-renewable natural energy resources, developing alternative resources of energy as a substitute of traditional fossil fuels has been risen. Biodiesel is among those alternatives and it is defined as an alternative fuel for diesel engines produced by chemically reacting a vegetable oil $^{1-5}$ or animal fat with an alcohol such as methanol or mono-alkyl esters of long chain fatty acids derived from a renewable lipid feed stock, such as vegetable oil. On the other hand, they were found to be problematic due to their greater viscosity which affecting piston injector deposits and oil thickening. Conversion of the oils to their alkyl esters reduced the viscosity to near the diesel fuel levels and produced a fuel with properties that were similar to petroleum based diesel long chain fatty acids derived from a renewable lipid fuel and which could be used in existing engines without modifications. The main advantages of using biodiesel fuels ${ }^{6-10}$ as $100 \%$ methyl or ethyl esters of vegetable oil and animal fat or biodiesel blends are producing less smoke and particulates, having higher cetane numbers and producing lower carbon monoxide and hydrocarbon emissions .

\section{Materials and Methods}

\section{Chemicals}

a) Sodium hydroxide

b) Methanol

c) water
Apparatus
a) Reflux condenser
b) Round bottom flask
c) Separating funnel
d) Water bath
e) Mechanical stirrer

\section{Precursor Oils}

\section{a) Soybean oil \\ Method}

The soyabean oil was purchased from the local market. Analytical grade reagents were used for all the analyses carried out without further purification. The Methanol used was a product of (99.7\% purity) while the sodium hydroxide was a product of Loba Chemicals (85\% purity). Other materials also used were specific gravity bottle, oven, furnace, Ferranti portable viscometer model VL, Abbe refracto meter, semi automatic Cleveland flash point tester and Hewlett Adiabatic Bomb Calorimeter model 1242.

The oil was characterized for the specific gravity using a specific gravity bottle, moisture content by the oven dry method, ash content by heating to dryness in furnace, viscosity by viscometer, the acid value, Saponification value, Iodine value and Peroxide value by titrimetry, refractive index using Abbe refract meter and flash point using the semi automatic Cleveland flash point tester). Percentage free fatty acid (\% FFA) (as oleic) was determined by multiplying the acid value with the factor 0.503 .

\section{b) Preparation of sodium methoxide}

Thirty milliliter of methanol was measured into a $250 \mathrm{~mL}$ flat bottom flask and covered immediately. $1.06 \mathrm{~g}$ of sodium hydroxide was carefully added into the methanol to make a solution which was made airtight. It was shaken and swirled for a few times until the $\mathrm{NaOH}$ was completely dissolved.

c) Biodiesel production and purification ${ }^{11-12}$ :

The transesterification reaction was carried out in a $500 \mathrm{~mL}$ airtight flat bottom flask containing a magnetic stirrer. The 


\section{International Journal of Science and Research (IJSR) \\ ISSN (Online): 2319-7064 \\ Index Copernicus Value (2013): 6.14 | Impact Factor (2014): 5.611}

$100 \mathrm{~mL}$ of the groundnut oil was measured into the flask and was heated to a temperature of $55^{\circ} \mathrm{C}$. The sodium meth oxide was then poured into the flask containing the oil and was immediately covered.

The temperature of the system was maintained between 60$65^{\circ} \mathrm{C}$ throughout the one hour reaction time. At the end of the reaction, the mixture was transferred into a separator funnel, left for $24 \mathrm{~h}$ and then the biodiesel separated from the glycerol. The biodiesel was then washed with warm water five times to a neutral $\mathrm{pH}$ to remove the glycerol, catalyst and other impurities. While the glycerol was not refined further but was kept for other uses.

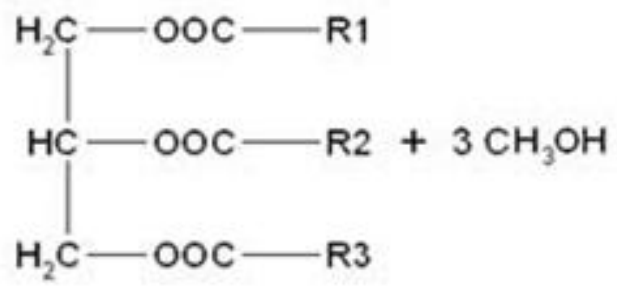

Triglyceride

Methanol

\section{Results and Discussion}

Initial run of Soybean oil was carried out in a magnetic stirrer which was successful. The amount of soybean oil taken was $100 \mathrm{ml}$ and the yield of biodiesel was $77 \mathrm{ml}$, which is quite high compared to the biodiesel yield from groundnuts. Thus soybean biodiesel is a better fuel as compared to groundnut biodiesel.

Table: parameters of soybean biodiesel

\begin{tabular}{|c|c|}
\hline Parameter & Soybean biodiesel \\
\hline Viscosity (cp) & 3.1 \\
\hline Yield (ml) & 77 \\
\hline Flash point ${ }^{\circ} \mathrm{C}$ & 127 \\
\hline Specific gravity & 0.765 \\
\hline Heat value (gm) & 3.27 \\
\hline $\mathrm{pH}$ & 3.5 \\
\hline
\end{tabular}

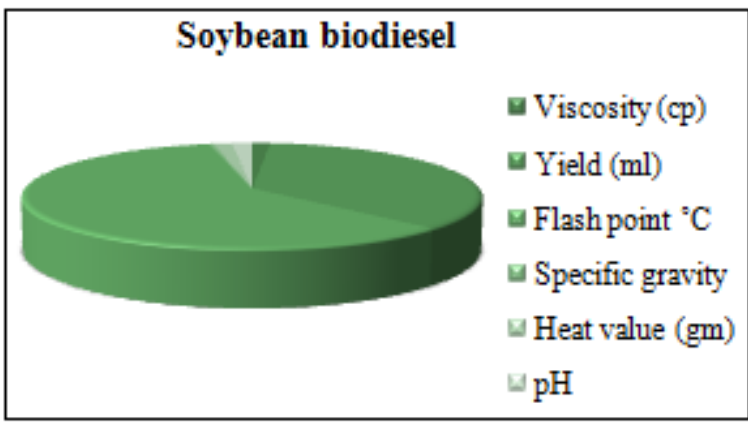

Graph 1: Parameter vs. soybeanoil

\section{Conclusion}

Biodiesel obtained from the soybean oil has been chosen as feed back for fuel production. In this work biodiesel from soybean oil were successfully produced and analyzed under

\section{d) Transesterification reaction}

As mentioned above biodiesel can be produced from straight vegetable oil, animal oil/fats, tallow and waste oils. There are three basic routes to biodiesel production from oils and fats:

- Base catalyzed transesterification of the oil.

- Direct acid catalyzed transesterification of the oil.

- Conversion of the oil to its fatty acids and then to biodiesel.

different observations (viscosity, flashpoint, specific gravity, yield, heat value). Based on the above observations the biodiesel obtained from the soybean was found to be a better alternative as renewable biodiesel source

\section{References}

[1] Akubugwo, I.E., G.C. Chinyere and A.E. Ugbogu, 2008. Comparative studies on oils from some common plant seeds in Nigeria. Pak. J. Nutr., 7: 570-573.

[2] Alamu, O.J., M.A. Waheed and S.O. Jekayinfa, 2007. Biodiesel production from Nigerian palm kernel oil: Effect of $\mathrm{KOH}$ concentration on yield. Energy Sustainable CrossRef Dev., 11: 77-82.

[3] Alamu, O.J., O. Dehinbo and A.M. Sulaiman, 2010. Production and testing of coconut oil biodiesel fuel and its blend. Leonardo J. Sci., 9: 95-104.

[4] 4.Alptekin, E.; Canakci, M., (2008). Characterization of the key fuel properties of methyl ester-diesel fuel blends. Fuel, 88 (1), 75-80 (6 pages)

[5] 10Antolin, G.; Tinaut, F. V.; Briceno, Y.; Castano, V.; Perez, C.; Ramirez, A. I., (2002). Optimisation of biodiesel productionby sunflower oil transesterification. Bioresour. Tech., 83 (2), 111-114 (4 pages).

[6] Baldwin, J. D.; Kilmowski, C. H.; Keesy, M. A., (1982). Fuel additives for vegetable oil-fueled compression ignition engines. Vegetable oil fuels. Proceedings of the international conference on plant and vegetable oils as fuels, ASAE, 82 4), 224.

[7] Banapurmath NR, Tewari PG, Hosmath RS (2008). Performance and Emission characteristics of a DI compression ignition engine operatedon Honge, Jatropha and sesame oil methyl esters. Renew. Energ.33: 1982-1988. 


\section{International Journal of Science and Research (IJSR) \\ ISSN (Online): 2319-7064}

Index Copernicus Value (2013): 6.14 | Impact Factor (2014): 5.611

[8] Boehman, A. L., (2005). Foreword biodiesel production and processing. Fuel Process. Tech., 86 (10), 1057-1058 (2 pages).

[9] Chinyere, I., Iwuoha, Collins N. Ubbaonu, Rophina C. Ugwo and Ngozi U. Okereke, 1995. Chemical and physical characteristics of palm, palm kernel and groundnut oils as affected by degumming. FUT Oweri, Nigeria.

[10] Chitra, P., P. Venkatachalam and A. Sampathrajan, 2005. Optimisation of experimental conditions for biodiesel production from alkali-catalysed transesterification of Jatropha curcus oil. Energ. Sust. Dev., 9: 13-18. Cianzio, Crop Sci., 36, 1466-1470 (1996).

[11] Van Gerpen, J., (2005). Biodiesel processing and production. Fuel Proc. Tech., 86 (10), 1097-1107 (11 pages

[12] Van Gerpen, J., B. Shanks, R. Pruszko, D. Clements and G. Knothe, 2004. Biodiesel analytical methods. National Renewable Energy Laboratory, Midwest Research Institute, Battelle, Colorado. http://www.nrel.gov/docs/fy04osti/36240.pdf 